\title{
EDITORIAL
}

\section{Tuberculosis in prisons: anatomy of global neglect}

\author{
J. O’Grady*,\#, M. Maeurer ${ }^{\dagger}$, R. Atun ${ }^{+, \S}$, I. Abubakar ${ }^{f}$, P. Mwaba ${ }^{\#, * * \# \#, ~ M . ~ B a t e s *, ", ~ N . ~ K a p a t a ~}{ }^{f}$, \\ G. Ferrara ", M. Hoelscher ${ }^{\top \uparrow}$ and A. Zumla*,\#
}

I nfectious diseases can be transmitted readily within prisons due to close contact between prisoners. Tuberculosis (TB) and HIV/AIDS are two important causes of morbidity and mortality from infectious diseases worldwide [1, 2]; prisons have become reservoirs for these diseases in many settings. TB prevalence among prisoners worldwide can be up to 50 times higher than national averages [3, 4]. Prisons account for a substantial proportion of the TB burden in the USA [5] and TB in prisons poses a major problem in the rest of the world, especially in countries of the former Soviet Union [6, 7] and sub-Saharan Africa (SSA) [8, 9]. Co-infection with HIV in prisoners with active or latent TB is well documented [4, 10, 11] and this presents difficult diagnostic and management challenges to prison health systems.

Apart from immunosuppression due to HIV, the high concentration of TB in prisons is often related to prisoner-associated risk factors such as poor nutrition, stress, drug and alcohol abuse, malnutrition, and associated chronic illnesses [3, 4, 9]. In addition, poor prison living conditions and mass incarceration [12] with inadequate ventilation, in such congregate settings, promote the transmission of Mycobacterium tuberculosis between prisoners. Such host and environmental risk factors facilitate new $M$. tuberculosis infections to progress to active disease, or may cause re-activation of latent TB in prisoners, the risk of which is at least an order of magnitude higher in prisons than in the general community [3]. Prisons serve as reservoirs of drugresistant TB [10-12] which is increasingly being reported from Eastern European [6, 7, 10, 11, 13] and SSA prisons [8, 9, 12, 14$16]$, where TB in prisons remains a neglected public health and human rights issue [15, 17-19]. However, the problem of TB in prisons is not only confined to Eastern European and SSA countries. In 1990-1991, alarming outbreaks of TB in New York State (USA) prisons recorded 171 prisoners with active disease, an incidence of 156/100,000 [20]. 39 out of the 171 prisoners had multidrug-resistant (MDR)-TB and, all but one, were infected

\footnotetext{
*Dept of Infection, Division of Infection and Immunity, University College London Medical School, Windeyer Institute of Medical Sciences, ${ }^{+}$Centre for Health Management, Imperial College London, and ${ }^{f}$ Tuberculosis Section, Dept of Respiratory and Systemic Infections, Health Protection Agency Centre for Infections, Health Protection Agency, London, UK. "University of Zambia and University College London Medical School (UNZA-UCLMS) Research and Training Programme, University Teaching Hospital, ${ }^{* *}$ Ministry of Health, and ${ }^{\# \#}$ National TB and Leprosy Program, Lusaka, Zambia. 'Dept of Microbiology, Tumour and Cell Biology, Karolinska Institutet, Stockholm, Sweden. ${ }^{\S}$ The Global Fund to Fight AIDS, TB and Malaria, Geneva, Switzerland. "Division of Infectious Diseases and Tropical Medicine, Medical Center of the University of Munich (LMU), Munich, Germany.
}

CORRESPONDENCE: A. Zumla, Dept of Infection, Division of Infection and Immunity, University College London Medical School, Windeyer Institute, 46 Cleveland Street, London, W1T 4JF, UK. E-mail: a.zumla@ucl.ac.uk with HIV. There was a high mortality rate of $87 \%$. The limited capabilities of the New York prison health services at that time resulted in the transfer of MDR-TB cases to a civilian hospital for further management, which resulted in the spread of MDR-TB. While effective control measures were instituted following this outbreak, TB in prisons still accounted for $4.2 \%(n=461)$ of the total TB burden in the USA in 2009 [5]. Of note, 94 cases of primary MDR-TB were reported in the USA in 2009 [5].

In the UK, TB has recently been recognised as an emerging health problem among prisoners [21, 22]. A retrospective 4-yr (20042007) study of 205 UK prisoners with newly diagnosed TB showed that over one-third of culture confirmed cases (48 out of 139) were resistant to isoniazid. The prisoners were more likely to be UK born ( $47 \%$ versus $25 \%$ ), white ( $33 \%$ versus $22 \%$ ) and to have pulmonary $\mathrm{TB}(75 \%$ versus $56 \%$ ) compared with all other TB patients seen in the UK during that period $(29,340$ cases aged $\geqslant 16$ yrs) [21]. The prevalence of TB in London prisoners is now 208 per 100,000; almost 15 times greater than the prevalence in the general population in the UK and almost five times that of the general population in London [22, 23]. Prisoners, homeless people and drug abusers collectively comprised $17 \%(321$ out of 1,941) of TB cases and $44 \%$ (31 out of 71) of sputum-smear positive drugresistant cases. There has been an almost 50\% increase in the number of TB cases in London in the past decade, rising from 2,309 cases in 1999 to 3,440 cases in 2009, and there is growing concern over the return of the "white plague" (TB) to London [24].

TB in prisons poses a particularly challenging public health, economic and social problem in SSA countries $[8,9,14,15,19]$ and countries of the former Soviet Union $[7,11,12,25,26]$. It is estimated that the total prison population in Europe is $>2$ million, with $>10.5$ million prisoners passing through the prison system each year [17]. The ratio of TB in prisoners to TB in the general community in Europe is estimated, on average, to be 15:1. Prisons in countries of the former Soviet Union have one of the highest prevalence rates of TB globally [2], with MDR-TB and its association with HIV/AIDS in prisoners and prison staff becoming a major public health concern [27]. The issue of drug-resistant TB in Europe, and its association with $\mathrm{HIV}$, has been highlighted by a recent report of the European Academies of Sciences Advisory Committee (EASAC) on drugresistant TB in Europe [13]. The report concludes that the EU has failed, so far, to respond adequately to the global TB threat and with the emergence of MDR- and extensively drugresistant TB in Eastern Europe, the rest of Europe is at risk of an ominous drug-resistant TB problem.

Worldwide, TB is considered the leading infectious cause of death for people living with HIV, and is responsible for an estimated 
$30 \%$ of AIDS deaths $[1,28]$. HIV infection and associated immune suppression is a major risk factor for the development of active TB in those who acquire new $M$. tuberculosis infection or have latent M. tuberculosis infection. Data from SSA show that HIV prevalence in prisons is more than twice the HIV prevalence of the general community [29]. Since TB and HIV epidemics are closely related, health services for prisoners must be aligned synergistically so that management with anti-TB drugs and antiretroviral therapy can be monitored effectively.

A 10-fold difference in the TB incidence between prison and civilian populations has been reported from SSA where prisons have clearly become reservoirs for drug-resistant TB $[3,9]$. High TB and HIV/AIDS endemicity in SAA countries means high rates of HIV co-infection in patients with TB: a potential time bomb for disrupting the recent progress made in TB and HIV control [30]. This is an area that must be urgently prioritised by politicians and international funding agencies. This urgency should not be underestimated given that the current data on drug-resistant TB in SSA prisons may be a gross underestimate due to a lack of resources and limited capability for effective drug-resistance screening [9]. Prisons globally share generic problems of poor accommodation, poor ventilation and inadequate healthcare facilities $[3,4,6,9,10]$. These tend to be more pronounced in middle- and low-income countries where the budgetary resources for the correctional system are much lower than that of high-income countries. Conditions experienced by those in prisons in the UK [21, 22, $31]$, USA [5, 32] and Western Europe [17, 33] are comparatively better than the difficult conditions prisoners face in SSA countries [14, 18, 19, 34] and parts of Eastern Europe [7, 11, 12].

The failure of TB control in prisons consequentially impacts on the community in general through visitors to prisons, prison staff and prisoners discharged into the community, therefore, improving TB control in prisons impacts on TB control in the community [30]. General guidelines (e.g. World Health Organization (WHO), Centers for Disease Control and Prevention (CDC), International Standards for Tuberculosis Care (ISTC) and National Institute for health and Clinical Excellence (NICE)) for TB identification, management and control in prisons need to be implemented in all prisons [4, 30, 35-40]. In high-income countries there should be management guidelines for prisoners with TB. In the UK, the NICE guidelines [38] emphasise the provision of education and support to the prisoner during treatment. Discharge planning is recommended and should be initiated in sufficient time before release or transfer of individuals from prison. A better liaison between the prison TB nurse or medical officer and local health authorities or primary care physician for continuity of treatment management should occur through follow-up appointments monitoring compliance, clinical recovery and treatment completion. It is suggested that the patient should be given TB information leaflets and a discharge letter which states the TB results, treatment accorded, and address of the local TB referral clinic. While guidelines exist, they are difficult to implement in practice as illustrated by ANDERSON et al. [21] who showed that only $48 \%$ of prisoners diagnosed with active TB completed treatment and $20 \%$ were lost to follow-up.

In the current economic situation, many middle- and lowincome countries, particularly Eastern Europe and SSA, have inadequate budgets for provision of quality and effective health services and they continue to rely on donor funding for support. This results in a lack of accurate data and information on the true scale of the problem of TB in prisons. Poor prison health services and inadequate laboratory diagnostics facilities for detecting TB and MDR-TB result in non-existent or poor data records. To justify specific requests for extra donor funds to improve health services for prisoners, it is essential that an evidence base is obtained through properly designed research into several important aspects of TB in prisoners and prison staff and their impact on TB control in the community. Such research must, however, not take advantage of the vulnerable prison population. Prisoners face restrictions on their liberty and autonomy, and have limited privacy and inadequate healthcare [36, 41]. Thus, they require specific protection when requested to participate in research, and any proposed research requires careful scrutiny by ethics committees and prison authorities. Adherence to the highest ethical values and the preservation of human rights is critically important in designing and conducting research involving prisoners [36, 41]. The acquisition of voluntary informed consent, protection of privacy and access to healthcare independently of consent to research, are crucial considerations. No official recommendations for ethical research in prisons are currently available in the majority of poor Eastern European and SSA countries and these must be developed.

Multiple factors fuel the transmission of TB, HIV and other infectious diseases within prisons. There is an urgent need to accurately define the factors driving TB in prisons, the magnitude of the problem and priorities for funding. Recommendations can then be made to governments and funding agencies to invest in the neglected area of health services for prisoners. A systematic approach to managing TB in prisons will lead to better optimised and cost-effective screening methods for TB, HIV and other infections, and ensure timely, rapid and accurate diagnosis and treatment of TB and HIV. Unless this is performed urgently, TB in prisons will remain a neglected global problem.

\section{SUPPORT STATEMENT}

J. O'Grady, P. Mwaba, N. Kapata, M. Hoelscher and A. Zumla received support from EuropeAID (Active Detection of Active Tuberculosis (ADAT)). J. O'Grady, M. Maeurer, P. Mwaba, N. Kapata, M. Hoelscher and A. Zumla have received grant support from the European and Developing Countries Clinical Trials Partnership (EDCTP) (TB Pan African Consortium for Evaluating Antituberculosis Agents (PANACEA), rapid evaluation of moxifloxacin in tuberculosis (REMOX) and TB NEAT) and UBS Optimus Foundation. A. Zumla also received support from the University College London Hospitals NHS Foundation Trust (UCLH)Comprehensive Biomedical Research Centre (CBRC) and UK Medical Research Council (MRC).

\section{STATEMENT OF INTEREST}

A statement of interest for R. Atun can be found at www.erj.ersjournals. $\mathrm{com} / \mathrm{site} / \mathrm{misc} /$ statements.xhtml

\section{REFERENCES}

1 Joint United Nations Programme on HIV/AIDS. Global report: UNAIDS report on the global AIDS epidemic 2010. Geneva, Joint United Nations Programme on HIV/AIDS, 2010.

2 World Health Organization. Multidrug and extensively drugresistant TB (M/XDR-TB). 2010 Global Report on Surveillance and Response. Geneva, World Health Oganization, 2010. 
3 Baussano I, Williams BG, Nunn P, et al. Tuberculosis incidence in prisons: a systematic review. PLoS Med 2010; 7: e1000381.

4 World Health Organization. Status Paper on Prisons and Tuberculosis. Copenhagen, World Health Organization, 2007.

5 Centers for Disease Control and prevention. Reported Tuberculosis in the United States, 2009. Atlanta, Centers for Disease Control and Prevention, 2010.

6 Aerts A, Habouzit M, Mschiladze L, et al. Pulmonary tuberculosis in prisons of the ex-USSR state Georgia: results of a nation-wide prevalence survey among sentenced inmates. Int J Tuberc Lung Dis 2000; 4: 1104-1110.

7 Stern V. The House of the dead revisited: prisons, tuberculosis, and public health in the former Soviet bloc. In: Gandy M, Zumla A, eds. The Return of the White Plague: Global Poverty and the "New" Tuberculosis. London, Verso, 2003; pp. 178-194.

8 Habeenzu C, Mitarai S, Lubasi D, et al. Tuberculosis and multidrug resistance in Zambian prisons, 2000-2001. Int J Tuberc Lung Dis 2007; 11: 1216-1220.

9 O'Grady J, Hoelscher M, Atun R, et al. Tuberculosis in prisons in sub-Saharan Africa: the need for improved health services, surveillance and control. Tuberculosis (Edinb) 2011; 91: 173-178.

10 Dubrovina I, Miskinis K, Lyepshina S, et al. Drug-resistant tuberculosis and HIV in Ukraine: a threatening convergence of two epidemics? Int J Tuberc Lung Dis 2008; 12: 756-762.

11 Ruddy M, Balabanova Y, Graham C, et al. Rates of drug resistance and risk factor analysis in civilian and prison patients with tuberculosis in Samara Region, Russia. Thorax 2005; 60: 130-135.

12 Stuckler D, Basu S, McKee M, et al. Mass incarceration can explain population increases in TB and multidrug-resistant TB in European and central Asian countries. Proc Natl Acad Sci USA 2008; 105: 13280-13285.

13 Fears R, Kaufmann S, ter Meulen V, et al. Drug-resistant tuberculosis in the European Union: opportunities and challenges for control. Tuberculosis 2010; 90: 182-187.

14 Centers for Disease Control and Prevention. Rapid assessment of tuberculosis in a large prison system - Botswana, 2002. Morb Mortal Wkly Rep 2003; 52: 250-252.

15 Noeske J, Kuaban C, Amougou G, et al. Pulmonary tuberculosis in the Central Prison of Douala, Cameroon. East Afr Med J 2006; 83: 25-30.

16 Lobacheva T, Asikainen T, Giesecke J. Risk factors for developing tuberculosis in remand prisons in St Petersburg, Russia - a casecontrol study. Eur J Epidemiol 2007; 22: 121-127.

17 Aerts A, Hauer B, Wanlin M, et al. Tuberculosis and tuberculosis control in European prisons. Int J Tuberc Lung Dis 2006; 10: 1215-1223.

18 Alexander J. Death and disease in Zimbabwe's prisons. Lancet 2009; 373: 995-996.

19 Todrys KW. Unjust and Unhealthy - HIV, TB and Abuse in Zambian Prisons. New York, Human Rights Watch, 2010.

20 Frieden TR, Fujiwara PI, Washko RM, et al. Tuberculosis in New York City - turning the tide. N Engl J Med 1995; 333: 229-233.

21 Anderson C, Story A, Brown T, et al. Tuberculosis in UK prisoners: a challenge for control. J Epidemiol Community Health 2010; 64: 373-376.

22 Story A, Murad S, Roberts W, et al. Tuberculosis in London: the importance of homelessness, problem drug use and prison. Thorax 2007; 62: 667-671.
23 Anderson L, Moore J, Kruijshaar M, et al. Tuberculosis in the UK: Annual report on tuberculosis surveillance in the UK 2010. London, Health Protection Agency Centre for Infections, 2010.

24 Zumla A. The white plague returns to London - with a vengeance. Lancet 2011; 377: 10-11.

25 Stern V. Problems in prisons worldwide, with a particular focus on Russia. Ann N Y Acad Sci 2001; 953: 113-119.

26 Bobrik A, Danishevski K, Eroshina K, et al. Prison health in Russia: the larger picture. J Public Health Policy 2005; 26: 30-59.

27 Raykhert I, Miskinis K, Lepshyna S, et al. HIV seroprevalence among new TB patients in the civilian and prisoner populations of Donetsk Oblast, Ukraine. Scand J Infect Dis 2008; 40: 655-662.

28 World Health Organization. Global tuberculosis control: WHO report 2010. Geneva, World Health Organization, 2010.

29 United Nations Office on Drugs and Crime. HIV and prisons in sub-Saharan Africa: opportunities for Action. Vienna, United Nations Office on Drugs and Crime, 2007.

30 O'Grady J, Mwaba P, Bates M, et al. Tuberculosis in prisons in sub-Saharan Africa - a potential time bomb. S Afr Med J 2011; 101 107-108.

31 Owers A. HM Chief Inspector of Prisons for England and Wales Annual Report 2008-2009. London, The Stationery Office, 2010.

32 The Correctional Association of New York. State of the Prisons 2002-2003 - Conditions of Confinement in 14 New York State Correctional Facilities. New York, The Correctional Association of New York, 2005.

33 Rodrigo T, Cayla JA, Garcia de Olalla P, et al. Effectiveness of tuberculosis control programmes in prisons, Barcelona 1987-2000. Int J Tuberc Lung Dis 2002; 6: 1091-1097.

34 Nyangulu DS, Harries AD, Kang'ombe C, et al. Tuberculosis in a prison population in Malawi. Lancet 1997; 350: 1284-1287.

35 Dara M, Grzemska M, Kimerling ME, et al. Guidelines for Control of Tuberculosis in Prisons: The Global Health Bureau, Office of Health, Infectious Disease and Nutrition, US Agency for International Development, 2009.

36 Elger BS, Spaulding A. Research on prisoners - a comparison between the IOM Committee recommendations (2006) and European regulations. Bioethics 2010; 24: 1-13.

37 Klopf LC. Tuberculosis control in the New York State Department of Correctional Services: a case management approach. Am J Infect Control 1998; 26: 534-537.

38 The National Collaborating Centre for Chronic Conditions, National Institute for Health and Clinical Excellence. Tuberculosis: clinical diagnosis and management of tuberculosis, and measures for its prevention and control. London, Royal College of Physicians, 2006.

39 Tuberculosis Coalition for Technical Assistance. International Standards for Tuberculosis Care (ISTC), 2nd Edn. The Hague, Tuberculosis Coalition for Technical Assistance, 2009.

40 World Health Organization. Tuberculosis Control in Prisons: A Manual for Programme Managers. Geneva, World Health Organization, 2000.

41 Seal DW, Eldridge GD, Zack B, et al. HIV testing and treatment with correctional populations people, not prisoners. J Health Care Poor Underserved 2010; 21: 977-985. 